\title{
FEASIBILITY OF A SURPLUS WOOD ENERGY INDUSTRY FOR THE STATE OF MICHIGAN
}

\author{
JO ANN KWONG ${ }^{1}$ and MITCHELL J. RYCUS ${ }^{2}$ \\ ${ }^{1}$ Resource Policy Economics and Management, School of Natural Resources, University \\ of Michigan, Ann Arbor, MI 48109 (U.S.A.) \\ ${ }^{2}$ Urban Planning Program, College of Architecture and Urban Planning, University of \\ Michigan, Ann Arbor, MI 48109 (U.S.A.)
}

(Accepted 8 March 1983)

\section{ABSTRACT}

Kwong, J.A. and Rycus, M.J., 1983. Feasibility of a surplus wood energy industry for the state of Michigan. Energy Agric., 2: 245--256.

Among the various forms of renewable energy, the utilization of surplus wood poses a possible alternative energy supplement for the state of Michigan. Surplus wood is available from unutilized industrial wood wastes, logging residues, underutilized species, and cull trees. It has been conservatively estimated that during the next 30 years, 450 million $t$ of surplus wood fiber in the state will be available for energy usage, capable of supplying approximately $1300 \mathrm{MW}$ of installed electric generating capacity or around 4000 million $1 /$ year of methanol. This paper examines the potential of producing liquid fuels and fuel wood for electric generation from surplus wood.

The need to carefully remove surplus wood from forests has long been recognized by forest management experts. Proper removal of these materials will make the forests healthier, more productive and will simultaneously add to Michigan's energy supply. Until now, the lack of a market for this wood and the high cost of harvesting it, has resulted in over-exploitation of high quality trees, followed by a lack of forest management to regenerate high productivity stands.

The growing and future opportunities of wood for energy can open markets which will allow for the intensive forest management practices that have been relatively ignored in the past. This paper discusses the expanding wood market and how it will directly and indirectly influence other economic markets.

The paper concludes that the use of wood by-products from all wood related industries, and the utilization of more trees with improved forest management, can not only supplement the present energy sources, but can actually improve the state's forest productivity, thereby contributing to the overall economic viability of the concept.

\section{OVERVIEW}

As the price of imported crude oil continues to rise, the United States is looking more towards alternative sources of fuel. The severe problems associated with coal and nuclear energy has focused greater attention on renewable sources; wood, direct sun, wind, and others. Wood is an abundant 
source of energy for the state of Michigan which can be utilized to help alleviate some of our energy problems.

This paper examines the potential of producing alcohol fuels and fuel wood for electrical generation from surplus wood in Michigan. It is estimated that there are 450 million $t$ of surplus wood in the state which could support either an additional $1300 \mathrm{MW}$ of installed electric generating capacity, or produce around 4000 million 1/year of methanol.

The strongest impact of the 1973 oil embargo and the later Iranian oil field shutdown was a shortage of liquid fuels. Alcohol fuels have been selected here for review since they can be substituted for gasoline and are one of the most sought after biomass energy forms. Alcohol fuels have been the center of considerable controversy with the increasing production of gasohol using ethanol from corn. Major issues surrounding increased production of gasohol focuses on the energy savings gained from the substitution, the possibility that competition between food and fuel may result, and the adverse environmental impacts which may be entailed. This paper is based on the contention that the state of Michigan has an abundance of unutilized surplus wood which can be used in the production of alcohol fuels.

Some of the reasons for the increasing enthusiasm toward wood energy sources include wood's excellent properties for conversion into energy and manufactured products, domestic availability, renewability, technological feasibility, and relatively low environmental impact. In fact wood energy offers potential environmental benefits such as constructive use of wastes that could otherwise cause pollution, the opportunity to improve forest productivity and eventually relieve logging pressures on some environmentally fragile lands, and the displacement of more harmful energy sources.

Economically speaking, alcohol fuels are available as a direct substitute for imported oil in all applications. Also, wood for energy could also have a positive effect on employment rates, particularly in rural areas. It could create new jobs in resource harvesting, manufacture and distribution, and servicing of conversion equipment, and the construction and operation of large-scale conversion facilities (OTA, 1980).

Besides being an inexpensive alternative to imported oil, a wood-fuel market can provide the opportunity to market the large quantities of rough, rotten, and otherwise unmarketable trees that abound in the forests. The market would encourage greater forest productivity by giving landowners financial incentives to remove these undesirable trees that crowd out quality timber.

In looking at the potential of wood for energy, it is necessary to consider regional variations, resource availability and the area's demand profile. These factors vary from region to region, depending upon locational differences (climate, forest cover, forest type, industry components, etc.). While huge quantities of surplus wood are available in all forested regions 
of the country, the kinds of wood available and the problems of utilizing it differ by area. Therefore, the research presented in this paper will focus on the issue of the potential of wood energy usage in Michigan.

\section{MICHIGAN SITUATION}

Nearly 95\% of Michigan's energy is supplied from other parts of the country and other parts of the world. Given projections for increasing population growth and higher energy demand, it may be wise to utilize sources of fuel which are readily available within the state.

Michigan's excess of annual timber growth over removals is one measure of an important potential source of fuel wood. Not all of this excess growth is available for use since approximately a third of the privately owned forest resource is withheld from the market. However, conceptually speaking, it could all be harvested without any reduction of growing stock (Hellman, 1977). The under-utilization of the wood grown is one of the major issues in forest management development. A country-by-country survey of the forests in the northern lower peninsula shows that very few counties even approach the annual allowable cut level (a harvest level established by the U.S. Forest Service for maximum management of the forests). In fact, many of the counties were below the $50 \%$ level indicating the extent of underutilization of existing stands.

It is conservatively estimated that during the next 30 years, about 450 million tonnes of surplus wood fiber could be available within the state (Hellman, 1977). The term "surplus wood fiber" refers to wood which has no commercial value at present, including dead, dying and decaying trees, residues from logging and sawmill operations, and that portion of annual growth which exceeds the commercial needs of the wood and paper products industry (Hiser, 1977). This potential 450 million $t$, depending on the technology used, could fuel an additional $1300 \mathrm{MW}$ of installed electric generating capacity or produce 4000 million 1/year of methanol, or some reasonable mix.

For more than 100 years, the forests have been harvested for only the long, straight, and most valuable trees, leaving behind the dead, diseased, and otherwise undesirable species. Economic considerations made it profitable only to take the "commercial" material. The veneer market uses only the highest quality trees, the pulp operations require certain species to the exclusion of others, and sawlog trees have to meet specific standards. However, continued removal of only the high quality trees has left many of the forests in poor condition. By creating a market for the tree tops, side branches, knotted trunks, etc., there is a more balanced harvesting of the fiorests. Thus, the utilization of the surplus wood improves the remaining stand of quality wood.

In Michigan over 800000 ha of young forest growth is in immediate need of thinning which could produce up to 73 million $t$ of wood. The once 
through removal of this fiber through environmental harvesting (harvesting the dead, dying and overmature, and leaving the good) would significantly improve the inventory and accelerate new growth while adding to the healthy stock left standing. Many trees appear healthy as they stand, but frequently they are decaying and have little or no commercial value and need to be harvested from the forest. Environmental harvesting includes Timber Stand Improvement (TSI) activities designed to improve the residual stand and provide fuelwood at the same time. TSI involves thinning and the removal of crooked, diseased, and undesirable trees from the forest so that the remaining trees can better utilize available nutrients, moisture, and sunlight. Thus, TSI practices are geared towards accelerating the growth of preferred tree species as well as improving the quality of individual stems. It is often considered a necessary evil under existing forestry practices to ensure that the forest remains in good condition. A stand left to grow without thinning results in trees with little commercial value. In the past, TSI has been done on a very limited basis, primarily due to the economics of this management practice. But with rising fuelwood prices, a landowner can hire a consultant, improve his woodlot and even make a small profit.

The advantages of thinning are apparent when it is pointed out that more wood is lost through fire, rot, insects, animals and other enemies of trees than are harvested annually. Forest fires cause significant damage, leaving the soils sterile, destroying valuable watersheds, and eliminating wildlife habitat. Crown Zellerbach (Wiegner, 1979) found that merely thinning a test plot of hemlocks caused the remaining trees to gain more than $60 \mathrm{~cm}$ a year in height, while an unthinned plot lost $78 \%$ of its trees to natural causes. Another consideration which shows the advantages of environmental harvesting is that in a fully stocked stand of $25 \mathrm{~cm}$ diameter trees, 3 out of 4 of them have to die or be cut to enable the survivor to become a sawlog tree $60 \mathrm{~cm}$ in diameter (Hellman, 1977).

Michigan's forests are in very poor condition as a result of repeated cutting of the best trees and leaving the poorer quality trees to grow (Hellman, 1977). The state-owned forest lands have not been planted, cultivated or harvested to the extent necessary to keep them viable. Thus, through environmental harvesting, Michigan could potentially double its present day harvest on state-owned lands while improving the growth and quality of its forests, increasing the land value, reducing the hazards of forest fires, improving wildlife habitat, and protecting the environment, while utilizing the much needed energy. By creating a market for the surplus wood, a hierarchy of wood types and uses is established which leads to a more balanced approach to forest management.

In addition to the wood that is available from environmental harvesting, wood residues such as sawdust, planer shavings, bark and trimmings are also readily available fuel sources. A typical sawmill produces nearly as much waste as it does lumber. Until recently, most forest products indus- 
tries considered these residues a waste disposal problem. With the economic incentive of higher oil and gas prices, the forest products industry has greatly increased its use of biomass to reduce consumption of fossil fuels. For example, between 1972 and 1979, the paper industry, which is the second largest manufacturing consumer of purchased energy, reduced its use of fossil fuel and purchased energy per tonne of output by more than 20\%. During this period, the energy generated from spent pulping liquors, bark and hogged wood waste rose from $42 \%$ of total energy consumption to $49 \%$, equivalent to almost 125 million barrels of oil annually. In addition, the pulp and paper industry leads the nation in cogeneration, utilizing heat first to generate electricity, and then for production processes (Marshall, 1980).

At present, whithout management, we are only growing trees at an estimated $61 \%$ of our productive capacity. In looking at the wood fuel availability for the state, based on annual timber growth figures, a significant amount of surplus wood fiber is projected in Michigan over the next 30 years. Over 10 million $t$ per year, which would amount to over 300 million $t$, is estimated to be available for use as fuel without competing with wood and paper products industry. Adding the 160 million $t$ of wood that could be harvested through TSI brings the total forest residue potentially available for fuel to 460 million $t$ of wood during the next 30 years, which could be used to produce 3800 million l/year of liquid fuels.

\section{ENERGY BACKGROUND}

Harvested wood can be converted to energy-related products in several ways: (1) direct combustion; (2) thermochemical processing through pyrolysis; and gasifications, and (3) aqueous processing, which involves the decomposition of wood in the presence of water. Combustible wood is most readily used as residential firewood in fireplaces and wood stoves, and as fuel for industrial boilers. However, increased use of this wood and the associated problems of its production and distribution has led to the development of other forms of wood fels, such as wood chips and pellets.

Mechanical "feller-bunches" and grapple skidders take tree logs, branches, leaves, twigs and bark and shred them up into chips of wood. These chips can be fed into woodburning equipment and burned at about $60 \%$ efficiency. Problems with varying moisture content, transportation and storage have resulted in the production of a more uniform form, the wood pellet. These products are densified wood which are uniform in moisture content, size, density, and BTU content, and they burn much better than green wood. They provide the advantages of increased ease of handling, improved burning efficiency, reduced boiler modifications (with minor modification, coal boilers can be accommodated to utilize wood as fuel), produce little dirt, and are easy to transport. Pellets burn with about $80 \%$ efficiency in a fluid bed combuster. 
In contrast to densified wood products which are unchanged from the basic wood form, various chemical processes may be performed on wood to provide different fuel products. One such process is called pyrolysis which is essentially the charcoal-manufacturing process. High-temperature heating breaks down the wood into gases, a tar mixture, and char. The most important product of pyrolysis is charcoal, which has a heating value of about 1.5 times the equivalent weight of the dry wood from which it was made (Zerbe, 1978).

Another process is hydrogenation, which may be utilized to gasify or liquify wood (as adopted from coal technology). In this procedure, hydrogen from water is added in a catalytic reaction at high pressures and temperatures. An experimental plant in Albany, OR is currently producing approximately 2 barrelsa of oil from about $1 \mathrm{t}$ of dry wood chips per day (this corresponds roughly to the $400 \mathrm{l}$ per oven-dried t describes in Rowell and Hokanson, 1977). Liquefication has also been experimented with wood fuel. The two wood-based liquid fuel possibilities most widely reviewed are methanol and ethanol. The competitive positions of these wood fuels are quickly changing with increasing uncertainty about middle eastern oil supplies.

Additional opportunities exist for expanded use of wood fuels for electric power generation. One approach is to use producer gas as a fuel for stationary internal combustion engines that would drive electric generators in power plants. Another possibility is to co-generate electricity and process steam. With co-generation, the normal $30 \%$ efficiency of power plants can be greatly expanded by using a given quantity of steam twice. First the steam is used under high pressure to operate turbines, then the exhaust steam from the turbine at low pressure is used to provide energy for industrial processes such as papermaking and kiln drying.

\section{ECONOMIC AND ENVIRONMENTAL CONSIDERATIONS}

The growing interest and future opportunities of wood for energy opens markets for wood which will permit intensive forest management that has in the past been relatively ignored. In addition, this expanding wood market will directly influence other economic markets.

The demand for more components of the total forest biomass allows a greater overall systems management approach. The need to carefully remove surplus wood from forests has long been recognized by forest management experts. Up until now, however, the lack of a market for this wood and the cost of harvesting has resulted in over-exploitation of the high quality trees, followed by a lack of forest management to regenerate high productivity stands. Large sections of the forests are overrun with timber that is of poor quality, but is still suitable for wood fuel. As in-

${ }^{a_{1} \text { barrel (US) }}=159.9871$. 
dustries increase their use of wood, a market will develop for the junk trees and landowners will be able to justify the cost of proper silvicultural practices.

A growing junk wood market may also positively affect other industries. For example, the increased demand for wood and the need to manipulate residues have improved the market for specialized log-handling equipment, sorting yards, and chip mills to handle the lower grade material. As these beome more common, the utilization of residues will increasingly work its way into the permanent industrial and marketing structure and will create a continuing demand for surplus wood. There is considerable evidence to support the argument that carefully managed harvesting of surplus wood resources could positively influence the wood products industry within the state.

The expanding wood market will also bring increased opportunities for both professional and technician level foresters, and others involved in the support activities of the harvest. Heck (1977) concludes that any large market for wood residue will have an impact on the economic condition of northern Michigan. Power generation, for instance, shows that a $10 \mathrm{MW}$, wood-fueled power plant could create 56 employment opportunities. These jobs would be broken down into 34 for harvesting the wood and 22 people involved with electrical generation. This potential employ. ment is of considerable importance, given this area's high rate of unemployment.

The study (Heck, 1977) also finds that shifting from fossil fuels to wood resources for the production of liquid fuels and electrical energy would reduce the energy dependency of the region as well as the state. It may also be particularly important from an economic growth perspective. Convincing evidence can be presented to suggest that guaranteed energy supply is an important location consideration for some industrial firms.

One of the major concerns of an expanding market for junk wood, is that the prices of other wood products may soar, but it is expected that there will be no important negative effect on other wood industries since substantially different kinds of wood are used (Tanner, 1977). The present industry has expanded because it is based on an available resource which does not include residue-type materials which are now expected to be used for energy. The existing timber based industries consist of those types of businesses requiring raw timber products. The raw timber resource must meet specific physical qualifications, depending on the end product. For instance, a veneer plant requires a higher quality log than a sawmill making pallet lumber. Thus, this sector of economy depends on quality trees for its material. The energy market, on the other hand, is less demanding of species mix and owood quality. This permits the use of non-merchantable logging, urban wood residues, and biomass. This hierarchy of wood types and uses will maintain independent markets for the products and energy sectors. 
Another economic consideration is the competitive position of alcohol fuels as an energy source. Several factors which are currently fluctuating will greatly influence the cost effectiveness of alcohol fuel. Escalating coal prices, compliance with environmental standards and combustion of coal, and middle eastem oil pricing may significantly improve the competitive position of wood energy. Technological advancement in the areas of wood fuel harvesting, storage, and handling are other factors which could also enhance the competitive position of wood-fueled energy.

Current estimates sugest that methanol could begin to compete economically with crude oil at $\$ 35$ a barrel. However, the competitive price is dependent upon the cost of the wood at the processor. In evaluating the economic position of wood fuels, the production of liquid alcohol fuels is highly valued (in comparison to uses through direct combustion or gasification) because the alcohols can substitute directly for imported oil in most energy applications. The energy value of the alcohol fuels can be viewed in terms of potential savings of premium fuels (oil and natural gas). Also, energy savings are gained by ethanol's ability to raise the octane of the gasoline that it is mixed with. If alcohol is used as an octane-boosting additive to gasoline, rather than solely. for its fuel value, it can replace up to the energy equivalent of $0.4 \mathrm{l}$ of gasoline per $\mathrm{l}$ of alcohol, assuming gasohol with $10 \%$ alcohol. Oil refineries alone, can save considerable amounts of energy because of this octane boost, since they cannot use lead additives to raise the octane of unleaded fuels (Plotkin, 1980).

Another potential economic advantage of producing alcohol fuels is the decentralized nature of the production system. This decentralization is dictated by the geographic distribution of forests within an area and the limitations on distance which are imposed by economical feedstock transport. Because of the relative simplicity of many biomass technologies and the lack of demanding physical operating conditions, some types of biomass facilities can operate on a smaller scale than is practical for other technologies, encouraging comparatively small scale operations.

Wood burning facilities also tend towards a decentralized approach since fuel logistics (wood fuel procurement, storage and handling, and transportation) limit the feasibility of using wood for electrical generation to small, decentralized plants, generally $10-50 \mathrm{MW}$. Transportation costs appear to be the greatest operating expense. Therefore, the location of the power plant should be as close as possible to its primary source of fuel to minimize costs (generally within $80 \mathrm{~km}$ ). This location of resources can pose a problem in the economic considerations. Again, regional characteristics play a significant role in determining the feasibility of using wood for energy.

Fragmentation of land ownership also poses potential problems in economic removal of surplus wood from piece-meal land areas, and in failure of independent landowners to regenerate cutover lands. Also, approximately a third of the privately owned forest resources in the state are withheld from the market. 
In addition to the economic issues, some of the compelling arguments for using surplus wood to supplement current energy sources are based on environmental grounds. One of the arguments is the positive effect upon the condition of the forests. Proper harvesting of the junk wood will make the forests healthier and more productive while simultaneously adding to our energy supply. The shift to utilizing surplus wood may also lead to a decrease in logging pressure on some environmentally valuable timber resources.

Some proponents of utilizing wood for energy argue that the movement will push towards more intesnive forest management and better environmental practices. Studies indicated that the technology and resources exist to increase forest productivity sufficiently to utilize wood energy. However, careful management is needed to supplement our energy sources with wood, without excessive disruption to other resource systems.

One of the greatest concerns of using wood energy is the impact of whole-tree harvesting on soil nutrients and the long term productivity of the forests. Although in most respects whole-tree harvesting produces the same results as traditional logging, it removes from the forest a much higher proportion of the biomass. The removal of small branches and leaves in whole-tree harvesting may be especially important because the leaves and twigs contain a disproportionately high concentration of plant nutrients. These nutrients might otherwise return to the soil with traditional harvesting. Moreover, it is known that the decaying wood on the forest floor provides important sites for nitrogen fixation. To the extent that whole-tree harvesting reduces the amount of wood left to decay on the forest floor, it will reduce the rate of nitrogen return to the forest soil.

Although the impact on the nutrient budget of the forest may be quite small and may not affect forest productivity in the first rotation after whole-tree harvesting, there is a strong possibility that productivity will be affected after successive harvest employing whole-tree methods (High, 1980). In addition, while utilizing all the surplus wood which is left in the forest after harvest, energy production may be maximized, but it may also leave the soil unprotected against erosion. Siltation and sedimentation from excessive erosion pose serious environmental problems in many areas. Also, the removal of this surplus may preclude the necessity of burning clearcut areas, and this could negatively affect those species which require fire to expose mineral soil for successful germination.

Whole-tree harvesting can have significant impacts upon wildlife also. All forms of wildlife that depend on woodland environments will be affected by increased utilization of forest products. These and other complexities of the forest ecosystems along with the varying characteristics of each forest type complicate intense forest management practices. In most problem areas, there are no cut and dry solutions. The environmental consequences of harvesting and other management activities are complex and site specific, which complicates the analysis of regional practices. There- 
fore, careful manipulation, within limits, can produce the supply of fuel wood needed, but there are critical areas which have to be carefully observed and respected.

Alcohol fuels can be used as direct substitutes for nuclear and fossil fuels. Hence, an evaluation of the environmental affects attributable to alcohol substitution should also be considered. This includes the alleviation of problems such as land stripping and mining from coal, radioactive leakage of nuclear plants, dependence on foreign oil, etc. Another possible benefit of substituting alcohol fuels for fossil fuels could be a net reduction in the emissions of carbon dioxide. However, the extent to which a substitution of biomass fuels for coal and other fuel would moderate the carbon dioxide buildup depends on the degree of substitution and the net carbon balance of the biomass fuel cycle.

The effects of using alcohol fuels as gasoline additives also pose a mix of environmental benefits and some potential damages. For example, particulate emissions can be substantially lowered and this reduction may also allow the use of oxidation catalysts to improve control of hydrocarbons.

\section{CONCLUSIONS}

This paper provides a background for examining the feasibility of utilizing wood for energy to supplement current energy sources in the state of Michigan through the production of liquid fuels and electrical generation. Based on the research presented here, it is recommended that wood for energy be further examined as a cost-effective means of utilizing wood power facilities. The generation of electrical power with wood as a fuel source is likely to be among the most promising uses for the large quantities of surplus wood in the state.

However, the production of liquid fuels is another viable alternative, particularly when it is considered that alcohol fuels can be used as direct substitutes for imported oil in most current applications. In trying to assess the value of wood residues for liquid fuels, one finds that a number of studies (Rowell and Hokenson, 1977) indicate that the current economics are not attrative. However, these cost estimates do not take into account the economic multiplying effects of new jobs, new industries and savings on waste disposal of wood by-products. Though no estimates are made in this paper on how much these multiplying effects can add to the value of a liquid fuel industry from wood residues, it is felt that the potential of almost 4000 million 1 of methanol obtainable each year from Michigan's forests is worthy of further analysis.

The benefits of wood's potentially clean burning characteristics also support the recommendation to look towards expanded implementation of wood-powered plants. In contrast to some of the other fuels that we currently depend on, the use of wood poses relatively little environmental impact, particularly with the proper particulate control mechanisms. How- 
ever, while wood offers benefits in the areas of sulfur oxides and carbon dioxide emissions, and some waste disposal alleviation, a number of potential environmental impacts have been described. Many negative impacts could result from mismanagement of the forest ecosystem. Yet, even with careful management, disturbances to the ecosystem are likely to result in impacts upon some components of the system. Given lag times for responding to disturbances, these impacts must be observed and responded to in the manner which will impose the least harm.

However, in discussing the nutrient balance and productivity effects, it should be stressed that the potential for wood at present, is viewed in an interim context. That is, wood can supplement our current energy sources as the technology is refined for other sources, such as solar energy. There is no need to view the wood for energy concept as a rigid commitment of our forest resources. It may be best to examine the feasibility of utilizing wood on a 30 year time horizon, which is approximately the estimated life span of a given wood-fueled plant. With this qualification, the impact of whole-tree harvesting upon the nutrient balance may be quite small and may not affect forest productivity until three or four successive harvests. A 30 year time span should only involve one or two rotations. If after 30 years wood is still a desired resource, we can then look towards intensive productivity through biomass plantations. Until then, the residuals, wastes, and environmental harvest products can be utilized.

The regional economic benefits associated with the development of wood energy is another very good reason to pursue this idea. Increased harvesting of wood fuel would create additional jobs and stimulate income within Michigan and other areas with available forests. The regional implications of these economic benefits would be particularly important since the major impact would be realized in the northern part of Michigan where most of the wood grows. This region of the state has been plagued with persistenly high unemployment and could benefit substantially from added employment and income opportunities (Hiser, 1977).

A final reason for recommending further study of implementing wood facilities is based on future economic conditions. The economics of wood as energy is encouraging and appear to be improving with escalating prices of other fuel sources. Greater concern (and regulation) for the environment and technological advancement of wood harvesting and combustion are other factors which could enhance the competitive position of wood fueled facilities.

In conclusion, it is recommended that wood for energy be given serious consideration in Michigan's overall energy plans. The following guidelines are suggestions for directing such plans:

(1) Develop an educational program which informs Michigan citizens of the basic wood characteristics and the nature of forest growth and capabilities so that they will be aware of the basis of environmental harvesting and the advantages of this management upon the forests. 
(2) Carefully develop management plans which will regenerate the forests, upgrade their quality, and accelerate their growth, while being sensitive to the limitations of the forest ecosystem. Forest productivity relationships should be carefully taken into account. Thorough understanding and application of forest productivity relationships means using the knowledge of soils and nutrients to objectively determine the amounts of residues that should be left in the wood to maintain long-term productivity under varying conditions.

(3) Grant tax incentives to forest owners so as to encourage the private landowner to maintain productivity after cutting and to grow and harvest trees scientifically.

(4) Respect the reasonable hierarchy of available wood sources by using industrial wood residues, first; residues left in the woods by logging and by forest cultivation next; and only then, if at all, harvesting entire stands primarily for energy fuel. This sequence will take advantage of work already done and costs already incurred. Further, it will minimize unnecessary conflicts between wood for energy and other purposes for which forest resources are managed and used. Direct each species and quality of wood into its highest value use (Heck, 1977).

\section{REFERENCES}

Heck, T., 1977. Wood fueled power generation: A potential source of energy for northern Michigan. Michigan Public Service Commission, Lansing, MI, 117 pp.

Hellmann, R,, 1977. Forestry management: Michigan's situation. In: Governor Milliken's Conference on Wood Energy, 29 November 1977, Lansing, MI. Michigan Public Service Commission, Lansing, $\mathrm{MI}$.

High, C., 1980. New England returns to wood. Nat. Hist., 89: 14.

Hiser, M., 1977. Governor Milliken's Conference on Wood Energy, 29 November, Lansing, MI. Michigan Public Service Commission, Lansing, MI.

Marshall, H., 1980. The role of wood in our energy future. Vital Speeches of the Day, June 15, 46: 217 .

OTA (Office of Technology Assessment), 1980. Biomass could provide $20 \%$ of US energy by 2000 , OTA says. Bioscience, $30: 631$.

Plotkin, S., 1980. Energy from biomass. Environment, 22: 6-40.

Rowell, R. and Hokanson, A., 1977. Methanol from wood: a critical assessment. In: Governor Milliken's Conference on Wood Energy, 29 November, Lansing, MI. Michigan Public Service Commission, Lansing, MI.

Tanner, H., 1977. The state of Michigan's role in the investigation of wood for energy. In: Governor Milliken's Conference on Wood Energy, 29 November, Lansing, MI. Michigan Public Service Commission, Lansing, MI.

Zerbe, J, 1978. The many forms of wood as fuel. Am. For., 84: 33. 